ISSN 2072-4292

www.mdpi.com/journal/remotesensing

Article

\title{
Performance Analysis of MODIS 500-m Spatial Resolution Products for Estimating Chlorophyll-a Concentrations in Oligo- to Meso-Trophic Waters Case Study: Itumbiara Reservoir, Brazil
}

Igor Ogashawara ${ }^{1, *}$, Enner H. Alcântara ${ }^{2}$, Marcelo P. Curtarelli ${ }^{1}$, Marcos Adami ${ }^{3}$, Renata F. F. Nascimento ${ }^{4}$, Arley F. Souza ${ }^{5}$, José L. Stech ${ }^{1}$ and Milton Kampel ${ }^{1}$

1 Remote Sensing Division, National Institute for Space Research (INPE), Avenida dos Astronautas, São José dos Campos-SP 1758, Brazil; E-Mails: mpedroso@ dsr.inpe.br (M.P.C.); stech@dsr.inpe.br (J.L.S.); milton@dsr.inpe.br (M.K.)

2 Cartography Engineering Department, State University of São Paulo, Rua Roberto Simonsen, 305, Presidente Prudente-SP 19060-900, Brazil; E-Mail: enner@fct.unesp.br

3 Regional Center for the Amazon, National Institute for Space Research (INPE), Parque da Ciência e Tecnologia do Guamá, Belém-PA 2651, Brazil; E-Mail: marcos.adami@inpe.br

4 Geopixel-Soluções em Geotecnologias, Rua Maestro Egydio Pinto, 190, São José dos Campos-SP 12245-902, Brazil; E-Mail: re_ffnascimento@ yahoo.com.br

5 ETEP Faculdades, Avenida Barão Rio Branco, 882, São José dos Campos-SP 12242-800, Brazil; E-Mail: arley.souza@etep.edu.br

* Author to whom correspondence should be addressed; E-Mail: igoroga@ gmail.com; Tel.: +55-12-3208-6484.

Received: 8 January 2014; in revised form: 7 February 2014 / Accepted: 12 February 2014 / Published: 20 February 2014

\begin{abstract}
Monitoring chlorophyll- $a$ (chl- $a$ ) concentrations is important for the management of water quality, because it is a good indicator of the eutrophication level in an aquatic system. Thus, our main purpose was to develop an alternative technique to monitor chl- $a$ in time and space through remote sensing techniques. However, one of the limitations of remote sensing is the resolution. To achieve a high temporal resolution and medium space resolution, we used the Moderate Resolution Imaging Spectroradiometer (MODIS) 500-m reflectance product, MOD09GA, and limnological parameters from the Itumbiara Reservoir. With these data, an empirical (O14a) and semi-empirical (O14b) algorithm were developed. Algorithms were cross-calibrated and validated using three datasets: one for each campaign and a third consisting of a combination of the two individual campaigns.
\end{abstract}


Algorithm O14a produced the best validation with a root mean square error (RMSE) of $30.4 \%$, whereas $\mathrm{O} 14 \mathrm{~b}$ produced an RMSE of $32.41 \%$ using the mixed dataset calibration. O14a was applied to MOD09GA to build a time series for the reservoir for the year of 2009. The time-series analysis revealed that there were occurrences of algal blooms in the summer that were likely related to the additional input of nutrients caused by rainfall runoff. During the winter, however, the few observed algal blooms events were related to periods of atmospheric meteorological variations that represented an enhanced external influence on the processes of mixing and stratification of the water column. Finally, the use of remote sensing techniques can be an important tool for policy makers, environmental managers and the scientific community with which to monitor water quality.

Keywords: chlorophyll- $a$; bio-optic modeling; time-series; MODIS

\section{Introduction}

Reservoirs in Brazil were built with several purposes, such as for hydroelectricity, recreation, navigation, irrigation and fisheries [1]. These multiple uses of water resources result in several environmental problems in which accelerated eutrophication is observed. When determining the trophic state of an aquatic system, one of the main indicators is the chlorophyll- $a$ (chl- $a$ ) concentration [2]. Chl- $a$ is also the primary component of almost all phytoplankton species, one of the main indicators of the presence of cyanobacteria in inland waters [3] and the primary optically active component in the study of water color [4]. All of these characteristics enhance the importance of monitoring chl- $a$ concentration in aquatic systems, not only because of its consequences to environmental and public health, but also for its role as a bio-indicator of algal blooms. Algal blooms are very common in eutrophicated aquatic environments and are a global problem aggravated by contamination and other sources of pollution [5]. Brazilian hydroelectric reservoirs have been affected by accelerated eutrophication processes, because of climatic characteristics that favor the proliferation of algal blooms and the high input of nutrients from waste water. In general, local populations depend on reservoirs for multiple uses of water; thus, monitoring chl- $a$ concentrations is a fundamental and strategic decision in the planning stages that enhances the value of a reservoir's services and benefit to human well-being [1].

Traditional chl- $a$ monitoring methods include field sampling and laboratory analysis; however, these methods are expensive, time consuming [6] and their spatial and temporal heterogeneity characteristics are inadequate for monitoring large studies areas [7]. Remote sensing techniques have been extensively used for monitoring chl- $a$ in aquatic systems [4,8-10]. The advantages of using remote sensing techniques to monitor chl- $a$ are: (1) the geographical coverage of satellite images, which provide information about the entire aquatic system; (2) remote sensing, which allows us to obtain information from inaccessible places; and (3) historical satellite images, which allow the inference of water quality information from the past records [11]. Thus, remote sensing can provide a regional and constant tool to monitor the spatial and temporal variability of water quality parameters, which is supported by Gons [7], who observed that the use of remote sensing techniques was a time saving, cost-effective and scientifically rewarding alternative. 
The use of remote sensing techniques was also enhanced by Mishra and Mishra [12], who determined that the remote estimation of biophysical parameters is essential for multi-temporal studies related to the primary production, carbon cycle, biogeochemical cycles and water quality. To estimate the biophysical parameters of aquatic systems, remote sensing techniques were applied to study water color. However, aquatic remote sensing studies are divided into two classes-Case 1 and Case 2-according to their study sites. Case 1 waters are those in which the absorption of chl- $a$ plays a dominant role in determining the total absorption. Moreover, other components, such as detritus and dissolved organic matter, covary with chl- $a$. Case 2 waters contain inorganic particles and/or color dissolved organic matter (CDOM) from land drainage that contribute significantly to the total absorption and scattering. Thus, the absorption by chl- $a$ is relatively less important in determining the total absorption [13]. Due to this difference, Case 2 waters are usually more complex than Case 1 waters, and standard algorithms used for chl- $a$ retrieval from Case 1 waters usually break down in Case 2 waters [14].

Several methods for estimating chl- $a$ concentration in different turbid waters (Case 2) with remote sensing have been investigated [4-12]. Many studies have suggested that remote spectroscopic measurements from the Moderate Resolution Imaging Spectroradiometer (MODIS) should be used to estimate chl- $a$ concentrations in Case 2 waters through empirical and semi-empirical algorithms $[4,15,16]$. However, in most of these studies, the spatial resolution is compromised, because of the use of MODIS $1-\mathrm{km}$ products that have a better spectral resolution. Thus, the use of MODIS 500-m daily reflectance products can provide good temporal responses and a higher spatial resolution that is more suitable for studies of inland waters.

The development of an empirical and semi-empirical algorithm for the 500-m products that are applied to a time series of MODIS images can improve the understanding of phytoplankton dynamics on the surface of an aquatic system. The use of remote sensing for monitoring aquatic systems can be an important tool for researchers, environmental managers and policy makers when developing predictive models, mitigation policies and management protocols to monitor algal blooms. In this paper, we analyzed the feasibility of applying MODIS 500-m daily surface reflectance products to achieve a common empirical and semi-empirical bio-optical model to retrieve the chl- $a$ concentration in the Itumbiara Reservoir, Brazil. In the region of this reservoir, Oliveira [17] identified approximately 109 species of phytoplankton, of which cyanobacteria species were predominant. Both models were calibrated and validated using data from two field campaigns in 2009. The models were then analyzed according to their applicability in a time series for the entire year of 2009.

\section{Materials and Methods}

\subsection{Study Area}

The study was conducted in the Itumbiara Reservoir $\left(18^{\circ} 25^{\prime} \mathrm{S}, 49^{\circ} 06^{\prime} \mathrm{W}\right)$, located in west-central Brazil between the states of Minas Gerais and Goiás (Figure 1). The climate in the region is classified as "tropical savanna", according to the Köppen [18] climate classification system, and has two well-defined seasons: dry (May-October) and wet (December-April). Monthly precipitation ranges from 
$5 \mathrm{~mm}$ in the dry season to $250 \mathrm{~mm}$ in the wet season. The air temperature average is high during the wet season $\left(24{ }^{\circ} \mathrm{C}\right.$ to $\left.26{ }^{\circ} \mathrm{C}\right)$ and a little lower in the dry season (approximately $20{ }^{\circ} \mathrm{C}$ ).

The region is typically a tropical grassland savanna, and the reservoir was formed by damming the Paranaíba River. Alcântara et al. [19] explained that the geomorphology of the basin was caused by its dendritic pattern, with the basin covering an area of approximately $814 \mathrm{~km}^{2}$ and a volume of $17.03 \times 109 \mathrm{~m}^{3}$.

Figure 1. Location and sampling sites in the Itumbiara Reservoir.

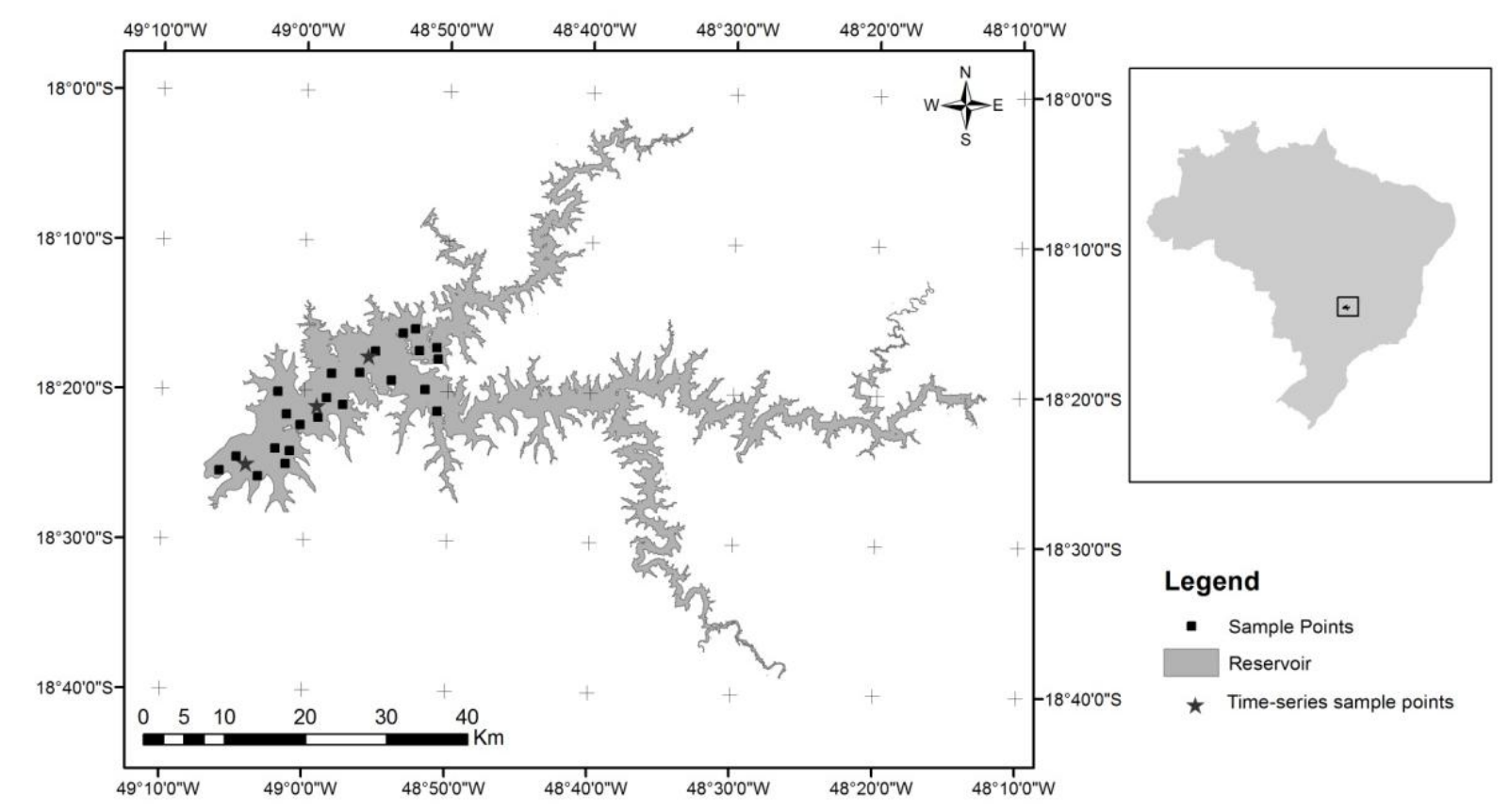

\subsection{Field Data}

Two field campaigns were undertaken in the Itumbiara Reservoir from 12 to 13 May 2009, and from 9-11 September 2009 [20]. Limnological variables, such as the concentration of chl- $a$, suspended organic and inorganic matter and dissolved organic and inorganic carbon, were obtained from a laboratory analysis of water samples that were kept at a cool temperature until delivery to the laboratory.

For chl- $a$ concentrations, water samples were collected from the surface of the water column and filtered through Whatman GF/F filters that were wrapped in aluminum foil and stored at freezing temperatures $\left(-20^{\circ} \mathrm{C}\right)$ until the analysis. Filters were analyzed according to Nush [21], which involved the extraction of chl- $a$ pigment using $80 \%$ ethanol followed by a thermal shock of the substance before the absorbance reading in the spectrophotometer. Concentrations were calculated according to Lorezen's [22] equations. Total suspended solids (TSS) were determined based on Wetzel and Likens [23], and this approach also used a filtering procedure of a known volume of water using a $\mathrm{GF} / \mathrm{C}$ filter that was pre-ashed at $480{ }^{\circ} \mathrm{C}$ and pre-weighed. Filters were stored in desiccators over silica gel. In the laboratory, each filter was dried at $60{ }^{\circ} \mathrm{C}$ for $24 \mathrm{~h}$ and weighed to determine the total suspended matter. The same filter was calcined at $480{ }^{\circ} \mathrm{C}$ for $1 \mathrm{~h}$ and reweighed to determine the inorganic particle concentration. Other physical parameters of the water samples, such as the temperature, 
$\mathrm{pH}$, dissolved oxygen (DO) and turbidity, were also measured using a YSI in situ multi-parameter sensor (Yellow Springs, OH, USA).

Remote sensing reflectance spectra above the water surface $\left(\mathrm{R}_{\mathrm{rS}}\right)$ were measured with an ASD field spectrometer (Analytical Spectral Devices, Inc., Boulder, CO, USA) following the method of Fougnie et al. [24] without a polarizer filter.

\subsection{MODIS Data}

The MODIS 500-m daily reflectance product from the Terra satellite was acquired via the National Aeronautics and Space Administration's (NASA) Land Processes Distributed Active Archive Center (LP DAAC) web interface using the Warehouse Inventory Search Tool (WIST).

The MOD09GA is comprised of surface spectral reflectance from atmospheric correction, and the atmospheric correction algorithms used in the MODIS reflectance products replace the aerosol climatological data when an accurate climatological dataset of aerosol optical thickness $\left(\tau_{\mathrm{a}}\right)$ is available [25]. This improves the algorithm's quality, because it is strongly driven by the $\tau_{\mathrm{a}}$ [15]. In addition to the accurate atmospheric correction, MODIS products also provided high radiometric sensitivity (12 bit) in 36 spectral bands spanning from $0.4 \mu \mathrm{m}$ to $14.4 \mu \mathrm{m}$. For MOD09GA, the spatial resolution is $250 \mathrm{~m}$ for Bands 1-2 (resampled to $500 \mathrm{~m}$ ) and $500 \mathrm{~m}$ for Bands 3-7. These bands were originally designed as "sharpening" bands for land studies and cloud detection [26]. Thus, because of its poor spectral resolution, the use of MOD09GA for water studies is limited [4]. However, because of its spatial resolution, the tradeoff for inland water studies is positive, because when the spatial resolution is poor, the water spectral response is contaminated with the land spectral response (one of the paths of radiance influence) [27].

\subsection{Algorithm Development}

An empirical and a semi-empirical algorithm were developed from the reflectance values of the seven spectral bands from MOD09GA. The empirical algorithm was developed using a forward stepwise regression analysis performed among reflectance that contains both a remotely-sensed sample point and an in situ chl- $a$ concentration in situ measurement. The step-wise regression was used as an automatic procedure to derive the "best" subset of bands to retrieve the chl- $a$ concentration by adding the bands to the regression. The parameters used to set the subset of the best spectral bands were the variations of the coefficient of determination $\left(\mathrm{R}^{2}\right)$. Thus, this subset was submitted to a multiple linear regression that was used to generate the empirical algorithm.

The semi-empirical algorithm was developed by analyzing the in situ $\mathrm{R}_{\mathrm{rs}}$ from each sample point and the bandwidth of MODIS. We used a band ratio between the band with the highest chl- $a$ reflectance as the reference and the band closest to the phytoplankton absorption peak. The band ratio approach was also used for the MODIS chl- $a$ products; however, they used the spectral bands with $1 \mathrm{~km}$ of spatial resolution. 


\subsection{Algorithm Calibration and Validation}

The calibration procedure for the empirical and semi-empirical algorithms and chl- $a$ concentrations were obtained through a linear regression analysis. We conducted this procedure using three datasets; one from each field campaign (May and September) and a third from the mixing of the other two datasets to analyze a dataset with a large range of chl- $a$ concentrations. For each dataset, model values were calibrated using a linear regression. Thus, for each dataset, one calibration $(y=a+b x)$ for each dataset was determined. A cross-validation procedure was adopted by using each calibration in another dataset, i.e., the May dataset was calibrated with the September and mixed dataset calibrations. Validations were evaluated by calculating the error estimator, such as bias, mean square error (MSE), mean absolute error (MAE) and root mean square error (RMSE) (Table 1).

Table 1. Error estimators used in this study. MAE, mean absolute error; MSE, mean square error; RMSE, root mean square error.

\begin{tabular}{cc}
\hline Estimator & Formulas \\
\hline Bias & Bias $=\frac{1}{n} \sum_{i=1}^{n}\left(y_{i}-x_{i}\right)$ \\
MAE & $M A E=\frac{1}{n} \sum_{i=1}^{n}\left|y_{i}-x_{i}\right|$ \\
MSE & $M S E=\frac{1}{n} \sum_{i=1}^{n}\left(y_{i}-x_{i}\right)^{2}$ \\
RMSE & $R M S E=\sqrt{M S E}$ \\
RMSE (\%) & $R M S E(\%)=\frac{R M S E}{y_{i, \text { max }}-y_{i, \text { min }}}$ \\
\hline
\end{tabular}

Note: $y_{i}$ and $x_{i}$ are the measured and predicted chl- $a$ concentrations, respectively. In the $i$-th sample; $y_{i, m a x}$ and $y_{i, m i n}$ are the maximum and minimum chl- $a$ concentrations, respectively.

\subsection{Time Series of Estimated Chl-a}

A chl- $a$ time series for 2009 was estimated by applying the algorithm with the best RMSE to all 365 images of the product, MOD09GA. However, several images had no data, because of the sensor's spatial coverage, which occasionally generates a gap in the image without any data. The daily MODIS reflectance data generated a time series of "predicted chl- $a$ " concentration for the entire year. The images were processed by implementing the best algorithm on an Interactive Data Language (IDL) and the Environment for Visualizing Images (ENVI) batch routine. This process not only retrieves the chl- $a$ concentration for a specific point, but it also spatialized the data on the reservoir surface throughout 2009.

\subsection{HANTS Filtering Method}

A filtering method was used to minimize the occurrence of outliers that appeared because of the presence of clouds or cloud shadows. The reflectance values from these objects are discrepant when compared with neighbors (in space or time). In addition, MOD09GA does not cover the entire study 
area every day, so a filtering method is required to remove the invalid data. The harmonic analysis of time series (HANTS) was developed based on the fast Fourier transform (FFT) method to consider time series of irregularly spaced observations and identify and remove cloud-contaminated observations [28]. Roerink et al. [28] showed that HANTS offered greater flexibility in the choice of frequencies and the length of the time series than the FFT algorithm. Additionally, this filtering method can determine the range of valid data and remove invalid data.

The HANTS was used to reconstruct the chl- $a$ time series to a seven-day time resolution. These points were filtered through the HANTS processing, and then, the whole series was reconstructed via Equation (1):

$$
C h l-a(t)=a_{i}+\sum_{i=1}^{n} a_{i} \cos \left(\omega_{i} t-\varphi_{i}\right)
$$

where $t$ is the Julian date, Chl- $a(t)$ is the fitted chl- $a$ value at time $t, a_{i}$ is the fitted coefficient, $n$ is the number of frequencies used, $\varphi_{i}$ is the fitted phase of the maximum chl- $a$ of the time series and $\omega_{i}$ was set according to the frequency.

\section{Results and Discussions}

\subsection{Environmental Characteristics}

The datasets collected from the two field campaigns represent two different periods of the hydrological cycle in the Itumbiara Reservoir. The first period, called the May campaign, is characterized by a rising flow regime, whereas the second period, called the September campaign, is characterized by a low flow regime according to Alcantara et al. [29], who classified the flow regimes based on interannual climate variations. Moreover, we analyzed the annual precipitation over the Itumbiara Reservoir from 1993 to 2010 to classify the years into two groups: typical and atypical. The classification was based on thresholds established from the sum of the average plus or minus the standard deviation of the series. Thus, 2009 was classified as a typical year that had an annual precipitation of $1533.8 \mathrm{~mm}$. Limnological variables varied during these two periods, and the comparisons between them are shown in Table 2. We observed that during the rising flow regime, the concentration of chl- $a$ was low. However, during the low flow regime, there was an increase in the chl- $a$ concentration. The same pattern could be observed in the DO concentrations that increased during the low flow period. However, the average $\mathrm{pH}$ value decreased during the low flow. These differences could be explained by the stratification and mixing processes in the reservoir. Alcântara [30] showed that for May 2009, the water column of the Itumbiara Reservoir was in the beginning of the mixed period. In September, however, it was in the beginning of the stratified period. These two processes of water column stability impact algal growth and vertical distribution and occur because variations in the temporal, vertical and horizontal structure of the physical processes promote changes in the pelagic zone [31]. These processes also promote several changes in the density structure of the water and in the distribution of chemical substances, which were observed by the $\mathrm{pH}$ variation. 
Table 2. Summary statistics for chlorophyll- $a$ (chl- $a$ ), total suspended solids (TSS), pH and dissolved oxygen (DO) for water samples collected in the Itumbiara Reservoir in 2009 during the May and September field campaigns.

\begin{tabular}{ccc}
\hline & May & September \\
\cline { 2 - 3 } & Mean \pm SD $($ Min-Max $)$ & Mean \pm SD $($ Min-Max $)$ \\
\hline Chl- $a(\mu \mathrm{g} / \mathrm{L})$ & $1.54 \pm 0.39(0.68-2.70)$ & $3.93 \pm 3.03(0.25-10.02)$ \\
TSS $(\mathrm{mg} / \mathrm{L})$ & $1.04 \pm 0.25(0.60-1.54)$ & $1.12 \pm 0.40(0.25-1.81)$ \\
$\mathrm{pH}$ & $7.63 \pm 0.13(7.48-7.90)$ & $6.99 \pm 0.47(6.29-7.90)$ \\
DO $(\mathrm{mg} / \mathrm{L})$ & $6.65 \pm 0.41(6.08-7.41)$ & $8.66 \pm 0.22(8.19-8.99)$ \\
\hline
\end{tabular}

\subsection{Algorithm Development}

The empirical algorithm was developed using a forward step-wise regression of the values from the two field campaigns $(n=50)$. This procedure was conducted since significance $\mathrm{F}$ was low and one $p$-value was high, then the forward stepwise regression can be used to develop the best model. This procedure was followed by a multiple linear regression of the most correlated bands. The forward step-wise regression (Table 3) revealed that the spectral Bands 1, 4, 5 and 6 were the most important MODIS channels for the correlation with chl- $a$ concentrations. Band 1 is located in the red channel related to the chl- $a$ absorption features. Band 4 is located in the green channel related to the reflectance peak of chl- $a$ (Figure 2). Band 5 is usually used for atmospheric correction, because of its proximity to the water absorption feature and also for the cirrus feature. Band 6 is generally used in inland water algorithms, because the water-surface-leaving radiance in this spectral band is insignificant, so this band is less affected by water types and depth. Bands 3 and 2 were excluded, because their inclusion in the analysis did not improve the $\mathrm{R}^{2}$ value. The reflectance from each of these bands for each sample point pixel were used in a multiple linear regression that retrieved a relationship among MODIS bands and chl- $a$ concentration, as shown in Equation (2).

Table 3. Step-wise regression analysis with the coefficient of determination $\left(\mathrm{R}^{2}\right)$, degrees of freedom (DF), F coefficient (F), variation of $\mathrm{R}^{2}$ and $p$-value.

\begin{tabular}{lcccccc}
\hline & Included Band & $\mathbf{R}^{\mathbf{2}}$ & $\mathbf{D F}$ & $\mathbf{F}$ & Variation of $^{\mathbf{2}}$ & $\boldsymbol{p}$-Value \\
\hline Band: 4 & 4 & 0.18 & 1.45 & 1.519 & $3.27 \%$ & 0.222 \\
Bands: 4, 1, & 1 & 0.35 & 2.44 & 3.167 & $9.32 \%$ & 0.051 \\
Bands: 4, 1, 6, & 6 & 0.42 & 3.43 & 3.024 & $4.84 \%$ & 0.039 \\
Bands: 4, 1, 6, 5, & 5 & 0.47 & 4.42 & 3.019 & $4.91 \%$ & 0.028 \\
Bands: 4, 1, 6, 5, 3, & 3 & 0.47 & 5.41 & 2.358 & $0.00 \%$ & 0.056 \\
Bands: 4, 1, 6, 5, 3, 2 & 2 & 0.48 & 6.40 & 2.016 & $0.88 \%$ & 0.086 \\
\hline
\end{tabular}

For the semi-empirical model, we evaluated the $R_{r s}$ and bandwidth of MODIS (Figure 2). Because the only spectral bands from MODIS sensor in the visible spectral range are Bands 1, 3 and 4, it was possible to plot them on the $R_{r s}$. Because chl- $a$ absorbs the blue light peak at approximately $440 \mathrm{~nm}$, this range has been used for Case 1 water algorithms to estimate chl- $a$ from space. A typical semi-empirical model used in Case 1 waters is the OC4v4 algorithm [32], which uses the band at $555 \mathrm{~nm}$ as the denominator and one of the three bands located near the green region (443, 490, 
and $510 \mathrm{~nm}$ ) as the numerator. This algorithm, which was developed for Case 1 waters, is based on the absorption of phytoplankton in the blue region and the reflectance of phytoplankton in the green region. For the Itumbiara Reservoir, the reflectance in the green region was higher than in the near-infrared (NIR). Thus, a typical chl- $a$ red-NIR algorithm would not work for these waters, which is consistent with Nascimento [20], who found that in the Itumbiara Reservoir, the total absorption was dominated by the absorption of detritus (60\%) and chl- $a$ (40\%). The band ratio between Bands 4 $(545-565 \mathrm{~nm})$ in the green region and $3(459-479 \mathrm{~nm})$ in the blue region was shown to be the most accurate, because of their proximity to the reflectance and absorption peaks of phytoplankton, which is observed in Figure 2.

Figure 2. $\mathrm{R}_{\mathrm{rs}}$ with the limits of Moderate Resolution Imaging Spectroradiometer (MODIS) Bands 1, 3 and 4.

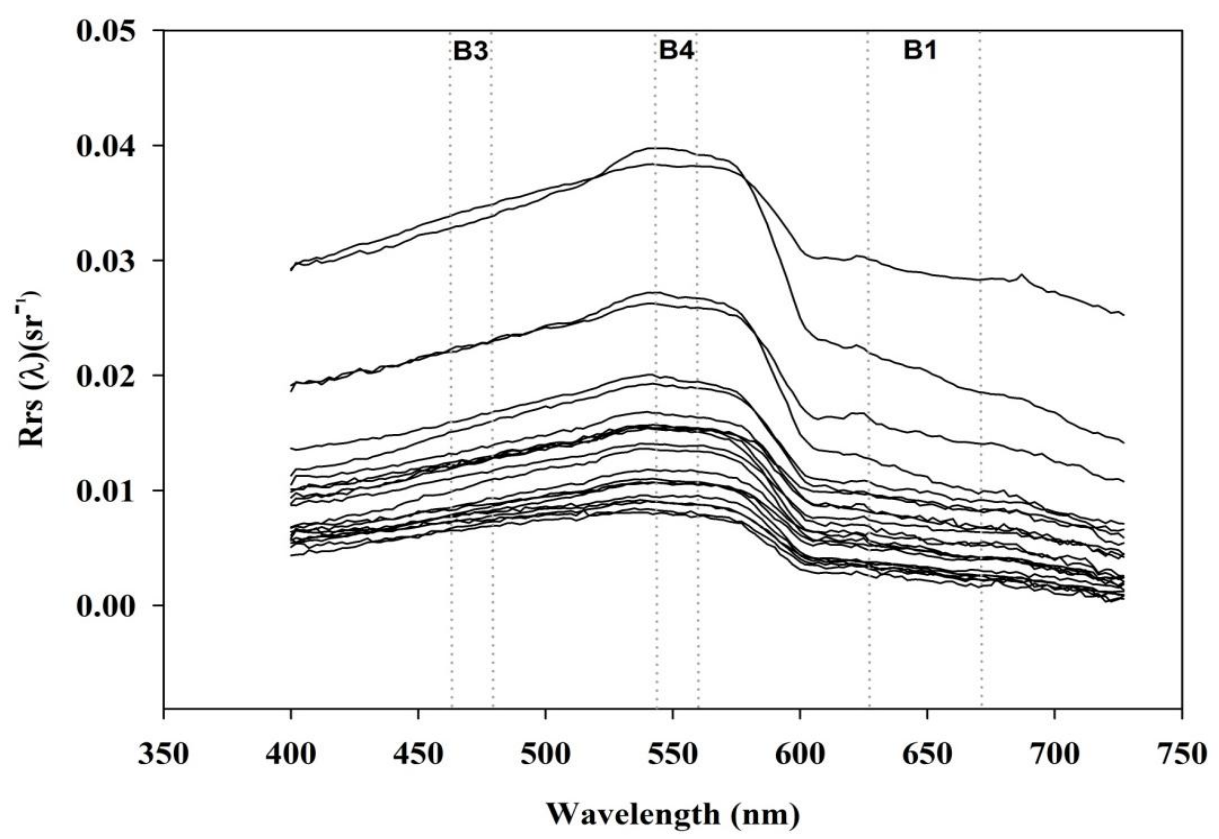

The empirical (O14a) and semi-empirical (O14b) algorithms were defined as in Equations (2) and (3), respectively:

$$
\begin{gathered}
O 14 a=5.6897+203.5419 \times B 1+(-151.0271 \times B 4)+(83.5912 \times B 5) \\
+(-170.4078 \times B 6) \\
O 14 b=\frac{B 4}{B 3}
\end{gathered}
$$

where $B 1, B 2, B 3, B 4, B 5$ and $B 6$ are the reflectance values from MODIS Bands 1, 2, 3, 4, 5 and 6, respectively, and Chla is the chl- $a$ concentration.

\subsection{Calibration and Validation}

Calibration for both models was conducted as described in Section 2.5. Thus, we applied Equations (2) and (3) to the MOD09GA product. The model values for each sample point were then used in a linear regression with the measurements of chl- $a$ concentrations. The first campaign 
calibration showed that the best result was produced with $O 14 a\left(R^{2}=0.206\right)$. For the second campaign dataset, the best $\mathrm{R}^{2}$ was also found with $\mathrm{O} 14 \mathrm{a}\left(\mathrm{R}^{2}=0.065\right)$. A mixed dataset combining the other two algorithms was also calibrated and showed the highest $\mathrm{R}^{2}$ values for both models: 0.223 for the O14a and 0.074 for the O14b. Calibration results are shown in Table 4, which not only includes $\mathrm{R}^{2}$ values, but also the adjusted $\mathrm{R}^{2}$ (Adj. $\mathrm{R}^{2}$ ) values, intercept and slope of each linear calibration. The Adj. $\mathrm{R}^{2}$ presented similar results, confirming the consistency in their performance. Calibration also showed the intercept and slope for each model, and the mixed dataset presented almost perfect intercept and slope values, with an intercept near zero and the slope at almost one. For each separate campaign, the values for the intercept and slope did not have the best performance.

Table 4. Calibration results for the two algorithms.

\begin{tabular}{cccccc}
\hline Model & $\mathbf{R}^{\mathbf{2}}$ & Adj. $\mathbf{R}^{\mathbf{2}}$ & Intercept & Slope & $p$-Value \\
\cline { 1 - 5 } & \multicolumn{7}{c}{ First Campaign $(\boldsymbol{n}=\mathbf{2 5})$} & \\
\cline { 1 - 5 } O14a & 0.206 & 0.171 & 1.105 & 0.216 & $>0.001$ \\
O14b & 0.157 & 0.121 & 2.767 & -0.712 & $>0.001$ \\
\hline \multicolumn{7}{c}{ Second Campaign $(\boldsymbol{n}=\mathbf{2 5})$} \\
\cline { 1 - 5 } O14a & 0.065 & 0.019 & 0.729 & 0.948 & 0.802 \\
O14b & 0.004 & -0.046 & 5.897 & -1.209 & 0.882 \\
\hline \multicolumn{7}{c}{ Mixed Dataset } & $(\boldsymbol{n}=\mathbf{5 0})$ & \\
\hline O14a & 0.223 & 0.206 & $2 \mathrm{E}-05$ & 1.000 & $>0.001$ \\
O14b & 0.074 & 0.053 & 7.439 & -2.891 & 0.004 \\
\hline
\end{tabular}

These results were similar to the ones found by $\mathrm{Wu}$ et al. [15], who judged that the $\mathrm{R}^{2}$ of multiple linear regressions showed a better performance when compared to a simple linear regression of a single bands or band ratios. The authors attributed the improvement of the multiple linear regression to the fact that it used more bands, which reduced the model's degree of freedom.

For accuracy assessment, models were validated by applying the calibrated equations from two datasets to the other dataset according to Equation (4).

$$
\text { chla }=\text { intercept }+014 \times \text { slope }
$$

Error estimators were calculated according to the equations in Table 2 and are shown in Table 5. Shaded areas enhanced the best error estimator for each campaign. For both cases, the use of a mixed calibration equation improved the accuracy of the algorithm. The use of a calibration with a smaller range of chl- $a$ concentration showed better accuracy results than the one with a large range. Using the May calibration, the RMSE was 42.052 and $36.018 \%$ for O14a and O14b, respectively, while the use of the September calibration produced an RMSE of $47.973 \%$ and $72.998 \%$ for the same algorithms. The use of $\mathrm{O} 14 \mathrm{~b}$ instead of O14a was appropriated for the second campaign using the May calibration and showed that when the empirical algorithm for the study area was used without changes to the water's biogeochemical composition, then the empirical algorithm is useful. It was also observed that the use of algorithms with a higher $\mathrm{R}^{2}$ in the calibration produced the lowest RMSE values; however, the exception was the May calibration for the O14b model in the second campaign, which produced a lower RMSE $(36.018 \%)$ and a lower $\mathrm{R}^{2}(0.157)$ compared to the $014 \mathrm{a}$ algorithm $\left(\mathrm{R}^{2}\right.$ of 0.206 and RMSE of 42.052) for the same calibration. 
Table 5. Error results for the two campaigns and three calibrations (shaded areas represent the lowest errors).

\begin{tabular}{cccccc}
\hline & & \multicolumn{2}{l}{ O14a } & O14b & \multicolumn{2}{c}{ O14a } & O14b \\
\cline { 3 - 6 } & & \multicolumn{2}{l}{ September Calibration } & \multicolumn{2}{c}{ Mixed Calibration } \\
\hline \multirow{5}{*}{ 1st Campaign } & Bias & 0.214 & 0.065 & -0.480 & -0.922 \\
& MAE & 0.800 & 0.370 & 0.715 & 0.993 \\
& MSE & 0.942 & 2.182 & 0.915 & 1.301 \\
& RMSE & 0.971 & 1.477 & 0.956 & 1.141 \\
& RMSE & 47.973 & 72.998 & 47.262 & 56.372 \\
& $(\%)$ & May Calibration & Mixed Calibration \\
\hline \multirow{5}{*}{ 2nd Campaign } & Bias & 2.356 & 1.847 & 0.546 & 1.048 \\
& MAE & 3.183 & 2.694 & 2.380 & 2.466 \\
& MSE & 16.876 & 12.380 & 8.612 & 10.025 \\
& RMSE & 4.108 & 3.519 & 2.935 & 3.166 \\
& RMSE & \multirow{2}{*}{42.052} & 36.018 & 30.040 & 32.412 \\
\hline
\end{tabular}

The use of three different datasets showing different conditions of flow regimes and chl- $a$ concentration allowed us to analyze the calibration that is more accurate for different environmental conditions. For a rising flow regime, in which the mixing process of the water column decreases the chl- $a$ content, the use of a mixed calibration produced better accuracy. For the low flow regime in which the stratification process is dominant, increasing the chl- $a$ concentration and the use of mixed calibration was also more accurate.

Compared to other studies, our error estimators were lower than other studies that also used spectral bands that were inappropriate for water studies. Le et al. [33] tested various MODIS band combinations, and their best performance produced an RMSE (\%) of $36.5 \%$ using bands with better spectral resolution for aquatic studies (Bands $11,12,14 \mathrm{~L}$ and $14 \mathrm{H}$ ). Because of the difficulties of bio-optical modeling of inland waters, the use of the MODIS 500-m product to estimate chl- $a$ concentrations produced reasonable errors (Table 5). This assumption was based on the SeaWiFS program, which is attempting to estimate chl- $a$ concentrations in open ocean waters that are within a 35\% accuracy [34]. In the case of estuaries, Le et al. [33] noted that an RMSE of 39.6\% for the red-green ratio algorithms was acceptable. Thus, the use of O14a and O14b with mixed calibrations is acceptable for tropical reservoirs with low chl- $a$ (varying from zero to $50 \mu \mathrm{g} / \mathrm{L}$ ).

We also compared our studies to the chl- $a$ algorithms implemented in the SeaWiFS Data Analysis System (SeaDAS); however, only two algorithms (OC2 and OC3) were able to retrieve the chl- $a$ data from the Itumbiara Reservoir. The algorithms were implemented using MODIS 1-km products resampled for $500 \mathrm{~m}$ that were atmospherically corrected by the Management Unit of the North Sea Mathematical Models (MUMM) algorithm using its default settings [35]. This algorithm was chosen because of its application for turbid waters. Table 6 shows the results of the OC2 and OC 3 algorithms for the Itumbiara Reservoir in the September campaign that produced the best results for our model. 
Table 6. Statistics for OC2 and OC3 applied by SeaDAS for the Itumbiara Reservoir.

\begin{tabular}{cccccc}
\hline \multicolumn{2}{c}{ OC2 $(\boldsymbol{n}=\mathbf{2 5})$} & \multicolumn{3}{c}{ OC3 $(\boldsymbol{n}=\mathbf{2 5})$} \\
\hline $\mathbf{R}^{\mathbf{2}}$ & $\boldsymbol{p}$-Value & $\mathbf{R M S E}(\boldsymbol{\%})$ & $\mathbf{R}^{\mathbf{2}}$ & $\boldsymbol{p}$-Value & RMSE (\%) \\
\hline 0.10 & 0.19 & 37.03 & 0.19 & 0.09 & 44.02 \\
\hline
\end{tabular}

Comparing the results for the same campaign, a better performance was observed for both algorithms (O14a and O14b) when compared to the OC2 and OC3. The RMSE (\%) for OC2 and OC3 was approximately 37 and $44 \%$ respectively, whereas for the same campaign, O14a and O14b produced an RMSE (\%) of approximately 30 and $32 \%$.

\subsection{Time Series}

A time series of chl- $a$ concentrations of the Itumbiara Reservoir was derived from the O14a algorithm and applied to MOD09GA. The time-series was filtered using HANTS to exclude the pixels with interference by clouds and shadows [36] and non-imagery days. Alcantara [37] analyzed the MODIS time series from 2003 to 2008 over the Itumbiara Reservoir and showed that from the 4,380 images, 2,976 images were cloud-free, which means that approximately $68 \%$ of the time, the images were useful for the time-series analysis. Non-imagery images occurred every 16 days, and in 2009, there were 23 non-imagery days for MODIS. HANTS was also used to interpolate the remaining data to a daily frequency. Figure 3 shows the filtered estimated chl- $a$ concentration for two points of the reservoir of the Itumbiara Reservoir for 2009. The first point is located near the reservoir's entrance, which is close to the Paranaíba and Corumbá Rivers, and the second point is located near the hydroelectric dam (Figure 1).

Figure 3. Filtered O14a time-series for two regions of the reservoir.

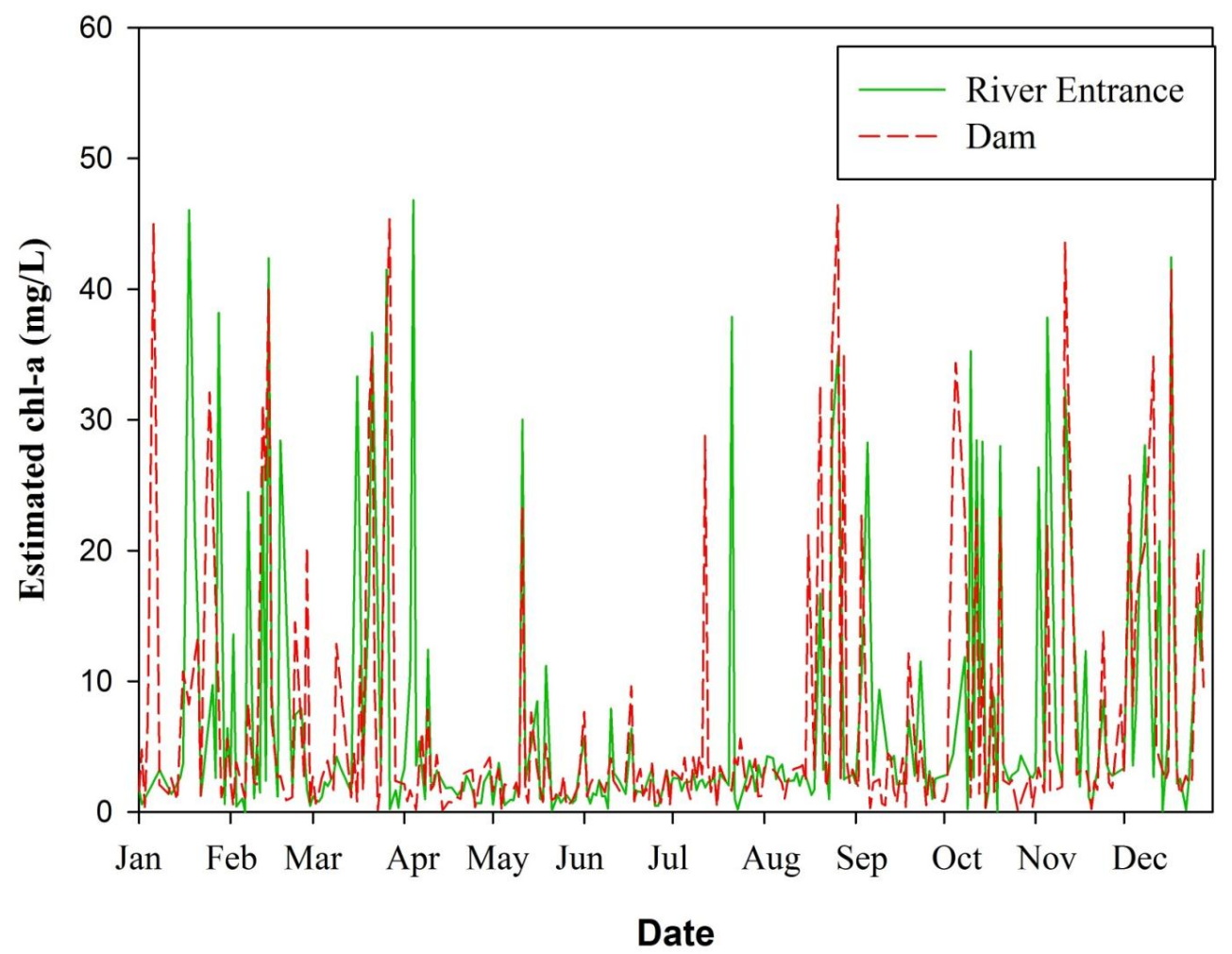


Both points showed low chl- $a$ concentrations during the dry season (from middle April to the end of August). However, during the dry season, a peak of the estimated chl- $a$ concentration was observed on 11 May for both points. To evaluate this, we reviewed the meteorological analysis of frontal events in Brazil and observed that among Days 4, 5 and 6 of May, intense winds from the east transported humidity from the ocean to the continent and caused precipitation in several regions of Brazil. The wind disturbance on the surface of the aquatic system can provoke a mixing of the water column [38]. In the Southern Hemisphere, wind-induced mixing is common during the passage of cold fronts $[39,40]$. After these events, mixing and several stratification processes occur on the water column [41]. These stability processes provoke disturbances of the thermal stratification, chemical stratification and ecological succession. Ogashawara et al. [42] showed that these cold front events could cause mixing in the water column, and a sudden variability of weather types could provoke such a mixing. Tundisi et al. [40] proposed a relationship between the stability of the water column and phytoplankton response. Thus, during mixing processes, phytoplankton is not predominant, whereas during the stratification of the water column, it is possible to have pre-bloom conditions.

Therefore, the low frequency of chl- $a$ peaks during the winter period was also related to external forces, because there were a high number of cold front entrances. Alcântara [30] showed that during the spring and summer when the heat balance was positive (heat gain), the water column stratifies. However, when the heat balance was negative, the water column exhibits mixing. The main effect of this differential heat and cooling of the water in the reservoir is on its quality. Thus, the response of chl- $a$ in a time series was affected by external variables, such as precipitation, wind intensity, wind direction and temperature.

Figure 4 shows the meteorological variables during the first two weeks of May used to analyze the estimated chl- $a$ peak on 11 May. Precipitation, maximum and minimum temperature, atmospheric pressure and wind speed were collected from a meteorological station located near the reservoir. There was a precipitation event on 5 May that occurred after a peak of wind speed on 4 May and with an increase of atmospheric pressure. This instability in the atmosphere occurred until 6 May, when the wind speed decreased along with the atmospheric pressure and the air temperature began to rise. During the high event of chl- $a$ (showed on Figure 3), the atmospheric dynamics were stable, which could be related to a stratification process of the water column.

Figure 4 shows that the rain event caused the mixing near the surface layer and reduced the chl- $a$ concentration. However, after the atmospheric and water column instability, the stable and stratified period enhanced the chl- $a$ concentration. This relationship was described by Tundisi et al. [40], who indicated that a precipitation event might drain the nutrients from an agricultural to aquatic environment. This action increased the pool of nutrients available for phytoplankton growth.

These processes of mixing and stratification of the water column associated with phytoplankton proposed by Tundisi et al. [40] were used to analyze the coherence of the estimated chl- $a$ time series. Thus, a heat balance analysis proposed by Alcântara [30] to identify the mixing and stratification periods was used to evaluate the estimated chl- $a$ time-series. This analysis ascribed a positive heat balance (heat gain) to the stratification of the water column and a negative heat balance to a mixing in the water column. Figure 5 shows the heat balance analysis from March 2009, to February 2010, that was calculated from the data at the Integrated System for Environmental Monitoring (SIMA) installed 
at the Itumbiara Reservoir $[43,44]$ near the dam. In the figure, the estimated chl- $a$ time series for the same pixels of the SIMA were plotted.

Figure 4. Meteorological variables for the period from 1-14 May.
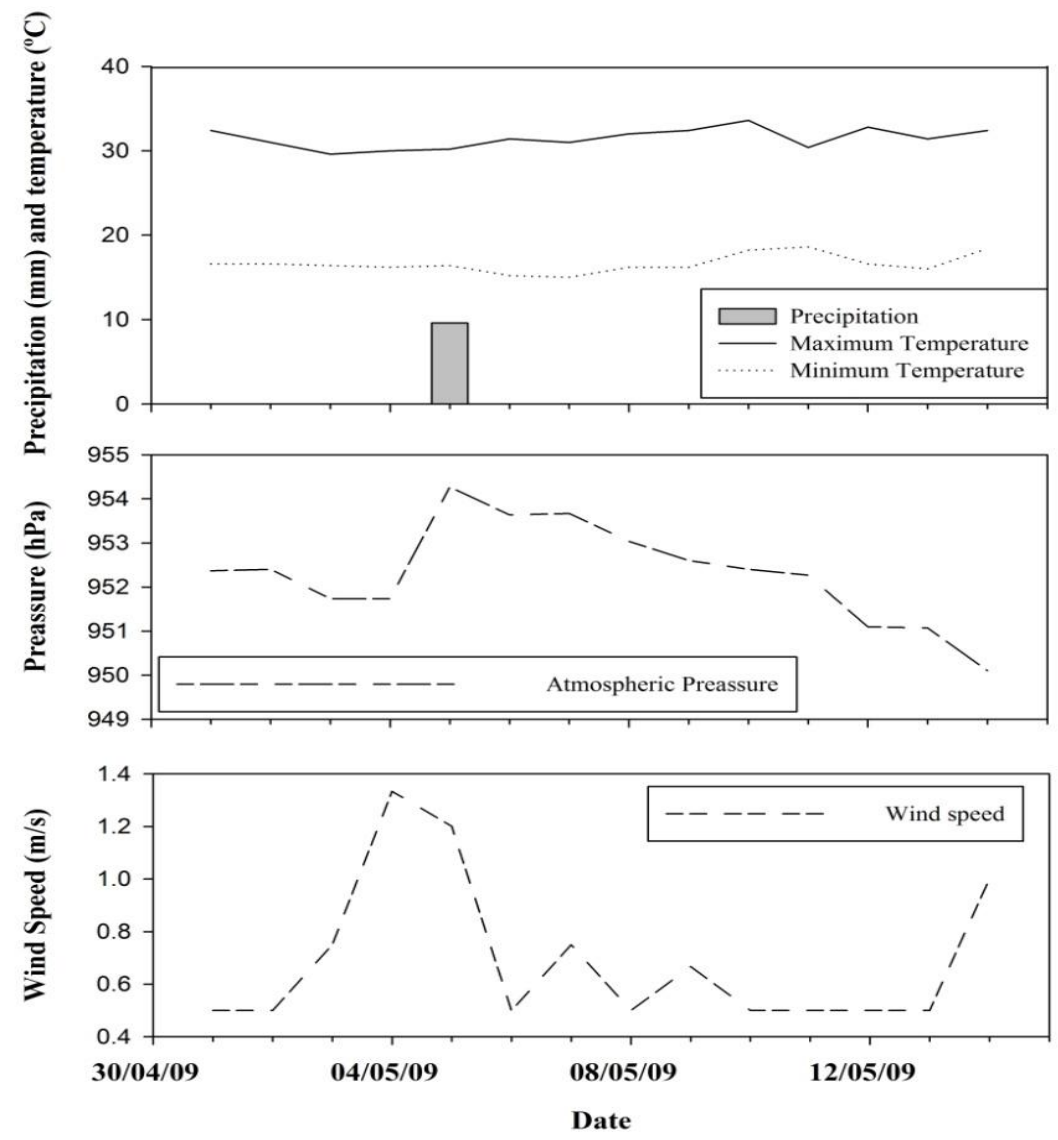

Figure 5. Water column temperature and estimated chl- $a$ time-series.

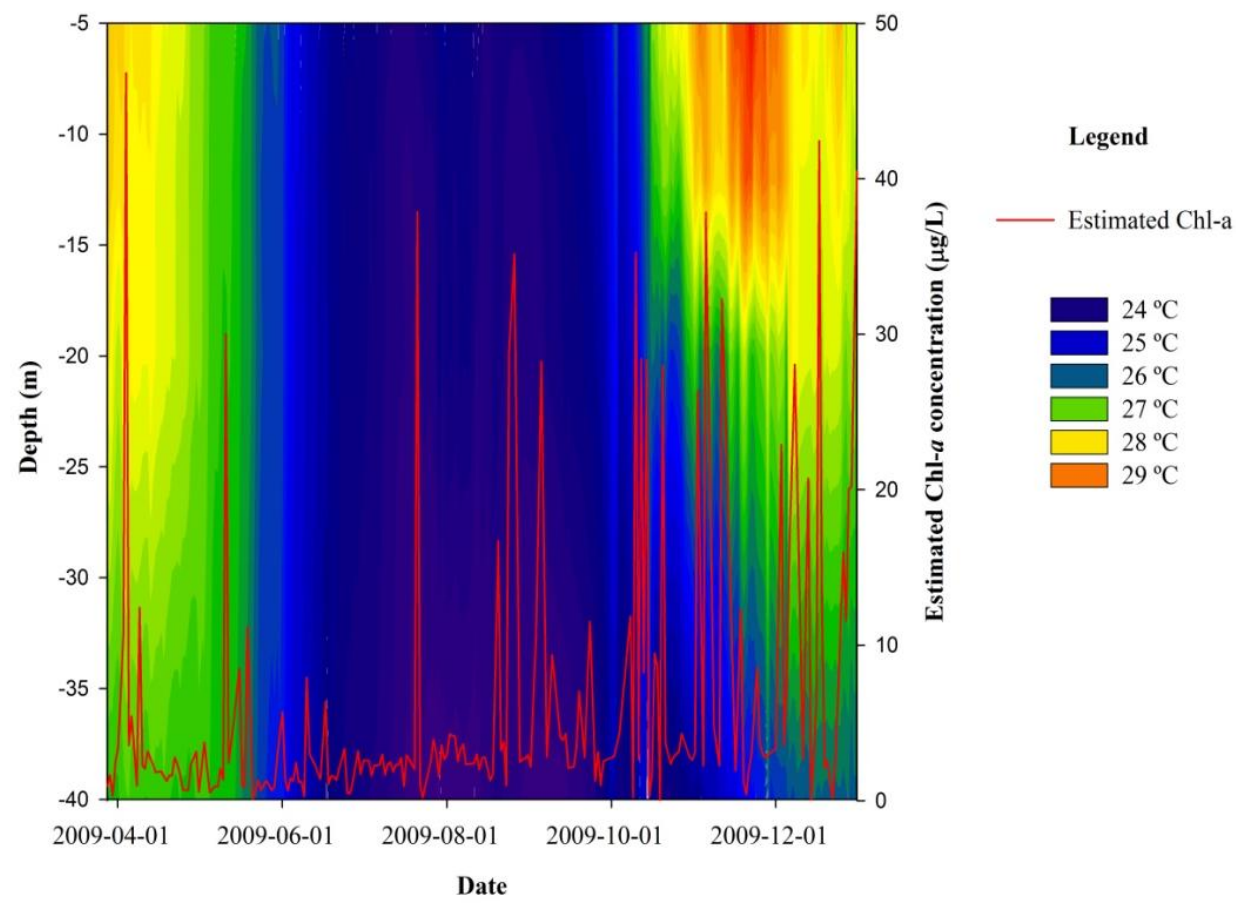


Figure 5 illustrates the importance of mixing and stratification processes on the phytoplankton succession changes of a tropical reservoir and the stability of the water column. During the austral winter, the cold front frequency and wind speed are the main parameters for the mixing processes in the Itumbiara Reservoir [41]. Because of the entrance of cold fronts, the relationship established by Tundisi et al. [40] could be observed, which showed that during cold front dissipation, pre-algal bloom conditions occur; therefore, the entrance of cold fronts could be related to a high concentration of chl- $a$. This relationship is observed in Figure 5, as well; during austral winter, when the frequency of cold fronts is higher, the dissipation of these cold fronts from the water column causes peaks of chl- $a$ concentrations. Therefore, when the water column is cold and mixed, the peaks of chl- $a$ could be related to meteorological events promoting the instability of the water column. This same relationship was observed in tropical aquatic systems in Africa, where the algal concentrations in an integrated column before and after strong winds were compared [45]. This study found that the concentration increased two- to three-fold after strong winds; however, during one particular event, the concentration increased more than five-fold. During stratified periods, it is possible to observe more chl- $a$ peaks; however, during the maximum stratification at the end of November, chl- $a$ peaks do not occur, which might be related to the lack of nutrients in the water column, because of the decantation resulting from the strong stratification process.

In situ measurements of chl- $a$ concentration from the Itumbiara Reservoir measured by the Federal University of Juiz de Fora showed that in a field campaign in November 2004, chl- $a$ concentrations varied from 7.17 to $57.91 \mu \mathrm{g} / \mathrm{L}$ from different sampling points. In March of 2005, chl- $a$ concentrations ranged from 1.33 to $143.55 \mu \mathrm{g} / \mathrm{L}$. Another field campaign in August 2005, produced chl- $a$ concentrations from 11.52 to $40.12 \mu \mathrm{g} / \mathrm{L}$. Considering the same thermal structure of 2009 , the smaller range was found in August, during the mixing period, while the larger range was found in March during the stratification period.

The spatial variability of the estimated chl- $a$ was analyzed by cropping the reservoir mask from the O14a product and performing a density slice among the chl- $a$ concentrations in the image. The period analyzed occurred during the mixing period from 2-10 August (Figure 6), and the influence of cloud cover [36] on the image of August 10 can be noticed, because most of the reservoir was unclassified because of the negative values. The pixels near the borders were unclassified, which showed that the algorithm worked well in not incorporating the influence from the soil. High concentrations of chl- $a$ were found in a linear stripe in various parts of the reservoir, because of a noise detector on the Band 5 $(1,230 \sim 1,250 \mathrm{~nm})$ image of the Terra MODIS geolocated data, which has severe and typical strips throughout the whole image. Because it can detect cirrus clouds and retrieve water vapor amounts [46], this spectral band is important, and it is worthwhile to consider it in the algorithm. Thus, the values of this stripe should not be considered in the analysis.

On 2 August, high chl- $a$ concentration were observed if compared to others images, which is explained by a variation of the weather conditions on $30 \mathrm{July}$, when wind speed and atmospheric pressure increased and air temperature decreased. These meteorological characteristics showed an instability with a mixing process in the water column, followed by a stratification in the bottom of the reservoir (Figure 5). This sequence of events [40] was responsible for the high chl-a concentrations observed on 2 August. Therefore, these findings suggest that algal blooms have a rhythm that is cross-correlated to meteorological parameters. Time-series analysis (Figure 3) showed that during 
spring (September) until mid-autumn (May to June), the monitoring of chl- $a$ should be the concern of the reservoir management administration. However, because of the high frequency of winter cold front entrances promoting the mixing of the water column, the concentration of chl- $a$ decreases along with its risks to human health.

Figure 6. Estimated chl- $a$ distribution in the Itumbiara Reservoir from O14a.

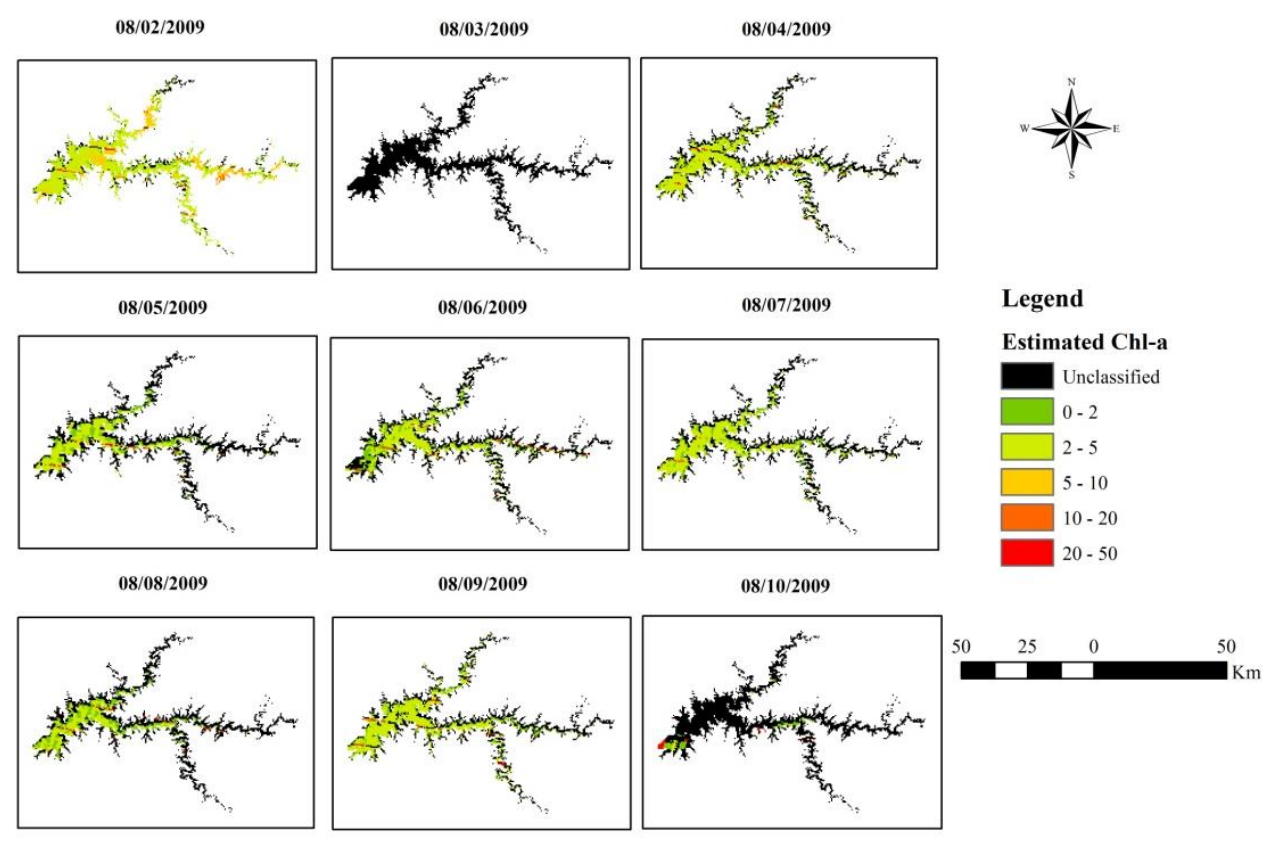

\section{Conclusions}

We developed an empirical (O14a) and a semi-empirical model (O14b) to retrieve chl- $a$ concentrations from MODIS 500-m daily reflectance products for the Itumbiara Reservoir. Both models were cross-validated with three different calibrations (Table 4), and the results of the validation are shown on Table 5. The O14a produced an RMSE of 30.40\%, and the O14b produced an RMSE of $32.41 \%$ by using mixed calibration (Table 2 ). We also applied two algorithms that use MODIS 1-km products (OC2 and OC3) implemented at SeaDAS to compare our findings. This comparison showed that both models (O14a and O14b) produced better RMSE (\%) using the mixed dataset calibration than the SeaDAS algorithms, which produced an RMSE (\%) of $37.03 \%$ and $44.0 \%$, respectively.

We also applied the O14a for the all of 2009 and analyzed the filtered time-series of the estimated chl- $a$ from two points located near the entrance of the reservoir and near the dam. The time-series of the estimated chl- $a$ concentration of the Itumbiara Reservoir in 2009 showed that during the summer and spring, there was a high frequency of algal blooms. During winter, however, the algal blooms were not common, and the few blooms that did appear on the time-series analysis were related to the stratification of the water column after a mixing event caused by variations in atmospheric stability. An observed difference between the two time-series also suggested that there is a migration of the algal bloom in the flow direction on normal days and in the anti-flow direction during frontal events.

Although the correlation and accuracy of our empirical and semi-empirical algorithms were satisfactory, we must remember that for most chl- $a$ concentrations, the empirical algorithms use sensors that have adequate spectral bands for aquatic studies. Thus, MODIS 1-km products are still preferable, because 
of their increased spectral resolution. However, for qualitative and rapid monitoring assessment of small to medium inland waters, the MODIS 500-m products are more appropriate than the 1-km products. Therefore, our two algorithms were essential to analyze the temporal and spatial distribution of algal blooms in the reservoir of the Itumbiara. To understand the dynamics of these algal blooms, the time series should be analyzed with other variables, such as bathymetry, meteorological variables and wind fields that affect the stability processes in the water column, as well as others water quality parameters. This integrated analysis will enable an understanding of the environmental factors contributing to the spatial and temporal variations in chl- $a$ in an aquatic system.

Compared to other medium spatial resolution sensors, MODIS is economical and potentially more viable for an environmental monitoring application, because of its high frequency of image acquisition. The use of algorithms to estimate chl- $a$ concentration will help environmental managers, policy makers and the population to easily identity the areas of algal blooms. The use of MODIS 500-m products for the monitoring of inland waters is more spatially accurate when compared to high spatial resolution products from SeaWIFS and MODIS chl- $a$ products. The time series analysis will allow environmental managers to produce information to predict the period of algal blooms that will be reflected in the costs of water treatment and availability, mainly for water supply reservoirs.

\section{Acknowledgments}

Special thanks to FAPESP Project 07/08103-2, INCT for Climate Change (CNPq 5737797/2008 and FAPESP 08/57719-9) and ELETROBRÁS-FURNAS. The authors thank Daniel Schaffer Ferreira Jorge for the assistance with image processing. Igor Ogashawara also thanks the Coordination for the Improvement of Higher Education Personnel (CAPES) for the scholarship grant.

\section{Author Contributions}

Igor Ogashawara is the main author who performed the analyses and wrote the paper with contributions from all the authors. Enner H. Alcântara, Marcelo P. Curtarelli and Renata F. F. Nascimento collected the data from Itumbiara Reservoir. Marcos Adami performed the HANTS algorithm for our dataset. Arley F. Souza provided the dataset from the project database. José L. Stech and Milton Kampel designed the research as well as provided funding for the field trips.

\section{Conflicts of Interest}

The authors declare no conflict of interest

\section{References}

1. Tundisi, J.G.; Matsumura-Tundisi, T.; Tundisi, J.E.M. Reservoirs and human well being: New challenges for evaluating impacts and benefits in the neotropics. Braz. J. Biol. 2008, 68, 1133-1135.

2. Mudroch, A. Planning and Management of Lakes and Reservoirs: An Integrated Approach to Eutrophication; UNEP International Environmental Technology Centre: Shiga, Japan, 1999. 
3. Reinart, A.; Kutser, T. Comparison of different satellite sensors in detecting cyanobacterial bloom events in the Baltic Sea. Remote Sens. Environ. 2006, 102, 74-85.

4. Moses, W.K.; Gitelson, A.A.; Berdnikov, S.; Povazhnyy, V. Estimation of chlorophyll-a concentration in case II waters using MODIS and MERIS data-Successes and challenges. Environ. Res. Lett. 2009, 4, 1-8.

5. Mendiondo, E.M. Global Review of Lake and Reservoir Eutrophication and Associated Management Challenges. Available online: http://wldb.ilec.or.jp/ILBMTrainingMaterials/ resources/eutrophication_challenges.pdf (accessed on 14 of Januery 2014).

6. Duan, H.; Ma, R.; Xu, J.; Zhang, Y.; Zhang, B. Comparison of different semi-empirical algorithms to estimate chlorophyll-a concentration in inland lake water. Environ. Monit. Assess. 2010, 170, 231-244.

7. Gons, H.J. Optical teledetection of chlorophyll-a in turbid inland waters. Environ. Sci. Technol. 1999, 33, 1127-1132.

8. El-Alem, A.; Chokmani, K.; Laurion, I.; El-Adlouni, S.E. Comparative analysis of four models to estimate chlorophyll-a concentration in case-2 waters using moderate resolution imaging spectroradiometer (MODIS) imagery. Remote Sens. 2012, 4, 2373-2400.

9. Morales, C.E.; Hormazabal, S.; Andrade, I.; Correa-Ramirez, M.A. Time-space variability of chlorophyll-a and associated physical variables within the region off Central-Southern Chile. Remote Sens. 2013, 5, 5550-5571.

10. Hadjimitsis, D.G.; Clayton, C. Field spectroscopy for assisting water quality monitoring and assessment in water treatment reservoirs using atmospheric corrected satellite remotely sensed imagery. Remote Sens. 2011, 3, 362-377.

11. Hadijimitsis, D.G.; Clayton, C. Assessment of temporal variations of water quality in inland water bodies using atmospheric corrected satellite remotely sensed image data. Environ. Monit. Assess. 2009, 159, 281-292.

12. Mishra, S.; Mishra, D.R. Normalized difference chlorophyll index: A novel model for remote estimation of chlorophyll-a concentration in turbid productive waters. Remote Sens. Environ. 2012, 117, 394-406.

13. Gordon, H.R.; Morel, A.Y. Remote Assessment of Ocean Color for Interpretation of Satellite Visible Imagery: A Review; Springer-Verlag: New York, NY, USA, 1983.

14. Dall'Olmo, G.; Gitelson, A.A.; Rundquist, D.C.; Leavitt, B.; Barrow, T.; Holz, J.C. Assessing the potential of SeaWiFS and MODIS for estimating chlorophyll concentration in turbid productive waters using red and nearinfrared bands. Remote Sens. Environ. 2005, 96, 176-187.

15. Wu, M.; Zhang, W.; Wang, X.; Luo, D. Application of MODIS satellite data in monitoring water quality parameters of Chaohu Lake in China. Environ. Monit. Assess. 2009, 148, 255-264.

16. Zhang, Y.; Lin, S.; Qian, X.; Wang, Q.; Qian, Y.; Liu, J.; Ge, Y. Temporal and spatial variability of chlorophyll-a concentration in Lake Taihu using MODIS time-series data. Hydrobiologia 2011, $661,235-250$.

17. Oliveira, M.T. O Fitoplancton Como Instrumento de Biomonitoramento da Qualidade da água do Reservatório de Cachoeira Dourada-Rio Paranaíba-GO/MG. Ph.D. Thesis, Federal Universidade de São Carlos, São Carlos, Brazil, 2010.

18. Köppen, W. Grundriss der Klimakund. Walter de Gruyter: Berlin, Germany, 1931. 
19. Alcântara, E.H.; Bonnet, M.P.; Assireu, A.T.; Stech, J.L.; Novo, E.M.L.M.; Lorenzzetti, J.A. On the water thermal response to the passage of cold fronts: Initial results for Itumbiara reservoir (Brazil). Hydrol. Earth Syst. Sci. 2010, 7, 9437-9465.

20. Nascimento, R.F.F. Utilização de Dados MERIS e in situ Para a Caracterização Bio-óptica do Reservatório de Itumbiara, GO. M.Sc. Thesis, Instituto Nacional de Pesquisas Espaciais, São José dos Campos, Brazil, 2009.

21. Nush, E.A. Comparison of different methods for chlorophyll and phaeopigment determination. Arch. Hydrobiol. Beiheft Ergebnisse der Limnol. 1980, 14, 14-36.

22. Lorenzen, C.J. Determination of chlorophyll and pheo-pigments: Spectrophotometric equations. Limnol. Oceanogr. 1967, 12, 343-346.

23. Wetzel, R.G.; Likins, G.E. Limnological Analyses; Springer: New York, NY, USA, 1991.

24. Fougnie, B.; Frouin, R.; Lecomte, P.; Deschamps, P.Y. Reduction of skylight reflection effects in the above-water measurement of diffuse marine reflectance. Appl. Opt. 1999, 38, 3844-3856.

25. Vermote, E.F.; Saleous, N.Z.E.; Justice, C.O. Atmospheric correction of MODIS data in the visible to middle infrared: first results. Remote Sens. Environ. 2002, 83, 97-111.

26. Vermote, E.F.; Kotchenova, S.Y.; Ray, J.P. MODIS Surface Reflectance User's Guide. Available online: http://modis-sr.ltdri.org/products/MOD09_UserGuide_v1_3.pdf (accessed on 17 January 2013).

27. Sentlinger, G.I.; Hook, S.J.; Laval, B. Sub-pixel water temperature estimation from thermal-infrared imagery using vectorized lake features. Remote Sens. Environ. 2008, 112, 1678-1688.

28. Roerink, G.J.; Menenti, M.; Verhoef, W. Reconstructing cloudfree NDVI composites using Fourier analysis of time series. Int. J. Remote Sens. 2000, 21, 1911-1917.

29. Alcântara, E.H.; Stech, J.L.; Lorenzzetti, J.A ; Bonnet, M.P.; Casamitjana, X.; Assireu, A.T.; Novo, E.M.L.M. Remote sensing of water surface temperature and heat flux over a tropical hydroelectric reservoir. Remote Sens. Environ. 2010, 144, 2651-2665.

30. Alcântara, E.H. Accessing the potential of satellite and telemetric data to evaluate the influence of the heat flux exchange in the water column mixing and stratification. Int. J. Geosci. 2012, 3, 899-907.

31. Imboden, D.M. The Impact of Physical Processes on Algal Growth. In Eutrophication: Research and Application to Water Supply; Sutcliffe D.W., Jone, J.G., Eds.; Freshwater Biological Association: Cumbria, UK, 1992; pp. 30-43.

32. O’Reilly, J.E.; Maritorena, S.; Siegel, D.A.; O’Brien, M.C.; Toole, D.; Chavez, F.P.; Strutton, P.; Cota, G.F.; Hooker, S.B.; McClain, C.R.; et al. Ocean Chlorophyll a Algorithms for SeaWiFS, OC2, and OC4: Version 4. In SeaWiFS Postlaunch Calibration and Validation Analyses; O’Reilly, J.E., Maritorena, S., Eds.; Goddard Space Flight Center: Greenbelt, MD, USA, 2000, pp. 9-19.

33. Le, C.; Hu, C.; English, D.; Cannizzaro, J.; Chen, Z.; Feng, L.; Boler, R.; Kovach, C. Towards a long-term chlorophyll-a data record in a turbid estuary using MODIS observations. Progr. Oceanogr. 2012, 109, 90-103.

34. McClain, C.R.; Feldman, G.C.; Hooker, S.B. An overview of the SeaWiFS project and strategies for producing a climate research quality global ocean bio-optical time series. Deep-Sea Res. II 2004, 51, 5-42. 
35. Ruddick, K.; Ovidio F.; Rijkeboer M. Atmospheric correction of SeaWiFS imagery for turbid coastal and inland waters. Appl. Opt. 2000, 39, 897-912.

36. Samanta, A.; Ganguly, S.; Vermote, E.; Nemani, R.R.; Myneni, R.B. Interpretation of variations in MODIS-measured greenness levels of Amazon forests during 2000 to 2009. Environ. Res. Lett. 2012, 7, 1-12.

37. Alcântara, E.H. Sensoriamento Remoto da Temperatura e dos Fluxos de Calor na Superfície da água do Reservatório de Itumbiara (GO). Ph.D. Thesis, Instituto Nacional de Pesquisas Espaciais, São José dos Campos, Brazil, 2010.

38. Imberger, J.; Patterson, J.C. Physical limnology. Adv. Appl. Mechan. 1989, 27, 303-475.

39. Tundisi, J.G.; Matsumura-Tundisi, T.; Arantes Junior, J.D.; Tundisi, J.E.M.; Manzini, N.F.; Ducrot, R. The response of Carlos Botelho (Lobo, Broa) reservoir to the passage of cold fronts as reflected by physical, chemical, and biological variables. Braz. J. Biol. 2004, 64, 177-186.

40. Tundisi, J.G.; Matsumura-Tundisi, T.; Pereira, K.C.; Luzia, A.P.; Passerini, M.D.; Chiba, W.A.C.; Morais, M.A.; Sebastien, N.Y. Cold fronts and reservoir limnology: An integrated approach towards the ecological dynamics of freshwater ecosystems. Braz. J. Biol. 2010, 70, 815-824.

41. Curtarelli, M.P.; Alcantara, E.H.; Rennó, C.D.; Stech, J.L. Modeling the effects of cold front passages on the heat fluxes and thermal structure of a tropical hydroelectric reservoir. Hydrol. Earth Syst. Sci. Discuss. 2013, 10, 8467-8502.

42. Ogashawara, I.; Zavattini, J.A.; Tundisi, J.G. The climatic rhythm and blooms of cyanobacteria in a tropical reservoir in São Paulo, Brazil. Braz. J. Biol. 2014, in press.

43. Stech, J.L.; Lima, I.B.T.; Novo, E.M.L.M.; Silva, C.M.; Assireu, A.T.; Lorenzzetti, J.A. Telemetric monitoring system for meteorological and limnological data acquisition. Verhandlungen Internationalen Verein Limnologie 2006, 29, 747-1750.

44. Alcantara, E.H.; Curtarelli, M.P.; Ogashawara, I.; Stech, J.L.; Souza, A.F. A system for environmental monitoring of hydroelectric reservoirs in Brazil. Revista Ambiente Água-An Interdiscip. J. Appl. Sci. 2013, 8, 6-17.

45. Ganf, G.G. Diurnal mixing and the vertical distribution of phytoplankton in a shallow equatorial lake (Lake George, Uganda). J. Ecol. 1974, 62, 611-629.

46. Savtchenko, A.; Ouzounov, D.; Ahmad, S.; Acker, J.; Leptoukh, G.; Koziana, J.; Nickless, D. Terra and aqua MODIS products available from NASA GES DAAC. Adv. Space Res. 2004, 34, 710-714.

(C) 2014 by the authors; licensee MDPI, Basel, Switzerland. This article is an open access article distributed under the terms and conditions of the Creative Commons Attribution license (http://creativecommons.org/licenses/by/3.0/). 